\title{
Poderia a ciência cognitiva ser dividida entre natural e cultural?
}

Daniel Luporini de Faria

Mestre em Filosofia da Mente, Lógica e Epistemologia pela UNESP (Marília)

\section{Resumo}

Partindo de seu conceito de prognoplasia ou transformação cognitiva, Marcos Barbosa de Oliveira, em seu instigante livro Da ciência cognitiva à dialética, sugere que a ciência cognitiva deveria ser divida em ciência cognitiva natural e ciência cognitiva cultural; isto porque a prognoplasia seria um fenômeno capaz de transformar em culturais aspectos pertinentes às ciências naturais. Desenvolvido inicialmente por Popper, tal fenômeno, chamado por ele de efeito Édipo, segundo a argumentação de Oliveira tenderia a transformar o homem num ser robotizado. Propomos aqui uma nova definição de naturalismo, argumentando que separar as ciências cognitivas traria mais problemas que benefícios ao mundo científico.

Palavras-Chave: Efeito Édipo; Ciência Cognitiva; Naturalismo.

\begin{abstract}
Parting from his concept of "prognoplasia" or cognitive transformation, the Brazilian philosopher Marcos Barbosa de Oliveira, in his thought-provoking book From Cognitive Science to Dialectics, suggests that cognitive science should be divided into a natural cognitive science and a cultural cognitive science. This is because prognoplasia would be a phenomenon capable of predicting or inducing either physical or cultural events. Initially described by Popper, this phenomenon, called by him the "Oedipus Effect", in the argument developed by Oliveira would tend to turn mankind into a robotic being. In this paper we propose a new definition of naturalism, arguing that separating the cognitive sciences would bring more problems than benefits to the scientific world.
\end{abstract}

Keywords: Oedipus Effect; cognitive Science; Naturalism.

(C) Filosofia e Educação - ISSN 1984-9605 - Volume 4, Número 2

Outubro de 2012 - Março de 2013 


\section{Introdução}

$\mathrm{N}$ a coletânea de textos que compõem o instigante livro Da ciência cognitiva à dialética (1999), Marcos Barbosa de Oliveira, mais precisamente no artigo intitulado "filosofia e ciência cognitiva", referindo-se à passagem da p. 54 do livro de Howard Gardner (1996) ${ }^{1}$, argumenta que, ao utilizar a expressão "auxiliar" para referir-se ao papel da filosofia para com as ciências empíricas na produção do conhecimento, Gardner intencionalmente atribui à filosofia uma função de subordinação em relação às ciências. Isso porque "auxiliares", traduzido do inglês handmaidens, denota o equivalente português a serva, criada.

Além da suposta ambiguidade semântica intencional presente no texto de Gardner, Oliveira afirma também que é falsa a asserção proferida pelo autor de que a ciência cognitiva ocupa-se da totalidade dos problemas epistemológicos, e apresenta três problemas genuinamente epistemológicos e filosóficos, que poderíamos resumir como sendo: a análise dos fundamentos da ciência, a avaliação das probabilidades prévias dos programas de pesquisa científicos com a contribuição no seu desenvolvimento, e o combate ao irracionalismo.

\section{Popper e o efeito Édipo}

O eixo central em torno do qual se articulam, para Oliveira, as críticas mais consistentes à posição naturalista, e, por conseguinte, à ciência cognitiva de modo geral, refere-se à asserção de que ao adotar os métodos e

1 "Vejo em ação um processo dialético, no qual os filósofos propõem certas indagações, disciplinas empíricas aparecem na tentativa de respondê-las, e então os filósofos cooperam com os cientistas empíricos na interpretação dos resultados e no estabelecimento de novas linhas de trabalho. [...] Em vez de serem os supremos árbitros ou as supremas vítimas do trabalho científico, os filósofos tem sido (e continuarão a ser) importantes auxiliares no estudo científico da cognição".

(C) Filosofia e Educação - ISSN 1984-9605 - Volume 4, Número 2

Outubro de 2012 - Março de 2013 
procedimentos característicos das ciências naturais, a ciência cognitiva tenderia a tratar como naturais aspectos da cognição que deveriam ser abordados como sendo culturais, havendo, pois, diferenças essenciais entre as ciências naturais e humanas, de modo que os métodos daquela não seriam adequados a esta.

Um dos principais problemas consequentes da suposta adoção irrefletida da "aparelhagem" metodológico-conceitual das ciências naturais pelas ciências humanas seria o famoso efeito Édipo, desenvolvido inicialmente por Popper em sua obra intitulada A miséria do historicismo $(1980)^{2}$. Na primeira parte da referida obra, Popper afirma que o efeito Édipo, em linhas gerais, seria o fenômeno em que o anúncio de uma previsão teria um impacto e/ou alteraria a ocorrência do próprio evento previsto.

Assim, devemos destacar dois pontos de suma importância: em primeiro lugar, o impacto das predições pode vir tanto a refutar tal predição, quanto corroborar tal predição (no sentido de que o prognóstico pode fazer com que o evento de fato ocorra $)^{3}$. Um segundo ponto a ser comentado versa sobre o evidente abalo que Popper, por meio de seu efeito Édipo, provoca em seu próprio construto teórico, minando-o em seus fundamentos. Isso porque Popper, além de adepto do princípio de unidade da ciência, era também empirista (a despeito de suas sérias divergências em relação aos positivistas lógicos), no sentido de que as observações desempenham um papel crucial na seleção de teorias ${ }^{4}$.

$2 \mathrm{O}$ efeito Édipo, a título de curiosidade, também é discutido em outras obras de Popper, em determinadas passagens de Conjecturas e refutações (1972, p. 68); A sociedade aberta e seus inimigos (1974, vol. 1, p. 35-36); e na sua Autobiografia intelectual (1977, p. 129-30).

3 Um exemplo (elaborado por Oliveira, 1999) deste segundo caso seria o de que ao prognosticar-se que a inflação vai subir, tal previsão poderia ocasionar uma reação preventiva dos agentes econômicos estipuladores de preços, de modo que eles, defendendo seus interesses, aumentariam o valor de suas mercadorias, o que faria com que a inflação viesse de fato a subir.

4 Poderíamos ser tentados a afirmar que dois princípios básicos do naturalismo, que seriam a unidade metodológico-conceitual entre as ciências e o empirismo ou existência de uma pedra de toque entre teorias e dados observacionais, se fizeram presentes em toda a tradição anglo-

(C) Filosofia e Educação - ISSN 1984-9605 - Volume 4, Número 2

Outubro de 2012 - Março de 2013 
Sendo assim, por que Popper desenvolveria um argumento tão deletério às suas próprias convicções obviamente naturalistas (pelo menos no sentido em que advoga a unidade entre as ciências e na medida em que se considera empirista), sendo que nem mesmo a terceira parte de $A$ miséria do historicismo, intitulada justamente "crítica das doutrinas antinaturalistas", contém uma resposta ao problema colocado por ele na primeira parte do livro?

Em sua Autobiografia intelectual (1977), Popper afirma ter julgado, por algum tempo, que a existência do efeito Édipo fosse capaz de servir como critério de distinção entre as ciências naturais e sociais. Porém, com a publicação de um artigo intitulado Indeterminism in quantum physics and in classical physics (1950) e de seu Postscript, sobretudo o segundo volume (1982), Popper reconsidera, procurando mostrar que, pelo fato do princípio de indeterminação (como o próprio título do artigo de 1950 sugere), característico da física quântica, também estar presente na mecânica clássica, o efeito Édipo não mais serviria para distinguir as ciências naturais das humanas.

A questão é que, embora tal estratégia pudesse preservar o naturalismo (desde que entendido a partir do princípio de que não haveria diferenças essenciais entre as ciências naturais e humanas), consequências desastrosas a outro compromisso fundamental da filosofia popperiana emergiriam, a saber: o princípio empirista. Pois, vigorando o princípio de indeterminação também nas ciências naturais, a capacidade de previsão das teorias fica comprometida. Logo, a própria ideia de que as observações desempenhariam um papel decisivo na seleção de teorias seria gravemente abalada.

saxônica da primeira metade do século XX. Já no que tange ao papel desempenhado pelas observações, para Popper, observa-se que elas seriam um tipo mitigado de corroboração, entendida como sendo sempre provisória, no sentido de que as teorias corroboradas por testes empíricos de caráter intersubjetivo sempre estariam sujeitas à revisão.

(C) Filosofia e Educação - ISSN 1984-9605 - Volume 4, Número 2

Outubro de 2012 - Março de 2013 
Com base na discussão proposta por Oliveira até o momento, nos parece óbvio que, quer o efeito Édipo circunscreva-se apenas ao domínio das ciências humanas, como Popper pensava no momento em que formulava o argumento em A miséria do historicicmo, quer se faça presente nas ciências naturais e humanas, como passou a entender no seu Postscript, o fato é que ambas as posturas, como já argumentamos, acarretam consequências gravíssimas ao seu corpus teórico.

Porém, o efeito Édipo abarcando tanto as ciências humanas quanto as naturais, ou circunscrevendo-se apenas ao domínio das ciências humanas, o importante é que uma vez colocada a ideia de que nas ciências humanas as previsões teóricas podem alterar os resultados que a própria teoria postula, parece claro que nas ciências sociais e também nas ciências cognitivas (das quais também fazem parte a filosofia da mente e determinadas linhas de pesquisa da antropologia, tal como a antropologia cognitiva), as consequências de tal ideia merecem ser estudadas.

O efeito Édipo, na argumentação de Oliveira (1999), assume o papel de um caso particular que reflete uma hipótese geral, que, em suma, seria a de que, no âmbito das ciências humanas, as teorias tendem a transformar seus objetos. A isto Oliveira denomina de prognoplasia, ou transformação cognitiva. No caso específico das ciências cognitivas, com base na afirmação um tanto provocativa de Dennett (1996) de que seríamos todos robôs, Oliveira teme que, tendo em vista o fenômeno da transformação cognitiva, seria possível que realmente viéssemos a nos transformar em robôs (algo não muito agradável de acordo com a definição de robô que Oliveira descreve), transformando o jeito "robotizado" de ser num hábito difícil de ser suplantado.

Tendo em vista tal argumento, desconfiamos que ele se baseia numa visão pouco crítica da realidade. Isso porque entendemos que, assim como o já citado exemplo da inflação parece corroborar tal hipótese, pensamos que

(C) Filosofia e Educação - ISSN 1984-9605 - Volume 4, Número 2 Outubro de 2012 - Março de 2013 
existem inúmeros exemplos em que saber de algo parece não alterar a conduta. Como exemplo, podemos citar a relutância de certas regiões da antiga URSS em aceitar a revolução mesmo com a massiva propagação dos ideais marxistas; ou o que dizer de pessoas que fracassam ao se proporem a alterar radicalmente determinados modos de agir, mesmo sabendo da perniciosidade de tais condutas. Um último ponto que gostaríamos de levantar seria o de que, se tomando a sério a argumentação de Oliveira, os pesquisadores em ciências humanas deveriam converter-se em ideólogos de teorias regidas somente por valores, de modo a abandonarem a proposta de descrição minimamente objetiva da realidade.

\section{Aspectos naturais e culturais da cognição}

A razão de levantarmos toda essa problemática em relação a uma velha questão ainda não resolvida pela filosofia da ciência deve-se ao fato de tomarmos a sério as críticas levantadas por Oliveira na obra Da ciência cognitiva à dialética contra o projeto naturalista no qual a ciência cognitiva se encerra.

A maneira como Oliveira (1999) lida com o problema (efeito Édipo), na verdade faz parte de um argumento mais geral, que visa minar os fundamentos do naturalismo, e que culmina com a proposta de um tratamento epistemológico diferenciado aos fenômenos ligados à cognição, que, segundo ele, deveriam ser divididos em naturais e culturais. Segundo o autor, tomar aspectos culturais da cognição como se fossem naturais seria adotar uma postura que culminaria numa visão acrítica da realidade.

Um dos caminhos traçados pelo autor na tentativa de explicar a pertinência de que de fato haveria fenômenos cognitivos que devessem ser abordados por um viés não naturalizante, logo, não devendo pressupor a noção de universalidade característica das ciências naturais, consiste em 
mostrar que a inferência dedutiva do silogismo não pode arrogar-se à generalidade. Além disso, apoiado nos trabalhos de campo efetuados por Luria (1990), argumenta que as faculdades mentais de nível superior derivam diretamente de fatores sócio-históricos ${ }^{5}$.

No livro: $O$ desenvolvimento cognitivo: seus fundamentos sociais $e$ culturais (1990), Luria realiza importante trabalho de campo nas regiões atrasadas do Uzbequistão e Kirghizia nos anos 1930-32, durante a reestruturação radical ocorrida na URSS, quando a eliminação do analfabetismo aliada à transição para uma economia coletivista efetuava-se, a fim de comprovar (como de fato parece fazer) se certas atividades cognitivas superiores, tais como a generalização e abstração, a dedução e inferência, a resolução de problemas, a imaginação e, por incrível que possa parecer, a percepção e a auto consciência ou sentimento da existência de um Eu, se efetivam somente no seio de certas culturas. Eis uma amostra de como a imersão em determinadas estruturas sócio-culturais são capazes de afetar nossas habilidades lógico-formais:

Sujeito: Abdurakhm, 37 anos, de um vilarejo isolado de Kashgar, analfabeto.

O seguinte silogismo é apresentado: no norte, onde há neve, todos os ursos são brancos.

Novaya Zemlya fica no norte e lá sempre neva. De que cor são os ursos lá?

S: há diferentes tipos de urso.

O silogismo é repetido.

S: eu não sei: eu já vi um urso negro, eu nunca vi outros [...] Cada localidade tem seus próprios animais: se é branco, eles são brancos; se são amarelos, eles serão amarelos.

$5 \mathrm{Na}$ verdade, a ideia de que todas as atividades cognitivas humanas fundamentais constroem-se a partir da história social encontra-se presente nas teses marxistas-leninistas, sendo aprofundadas por Vigotsky, de modo que seus trabalhos serviram como base para grande parte dos estudos desenvolvidos pela escola soviética de psicologia na primeira metade do século XX.

(C) Filosofia e Educação - ISSN 1984-9605 - Volume 4, Número 2

Outubro de 2012 - Março de 2013 
E: mas que tipos de ursos há em Novaya Zemlya?

S: nós sempre falamos somente sobre o que já vimos, nós não falamos sobre o que não vimos.

E: Mas o que minhas palavras implicam? O silogismo é repetido.

S: bem, é assim: nosso czar não é como o seu e o seu não é como o nosso. Suas palavras somente podem ser respondidas por alguém que esteve lá, e se uma pessoa não esteve lá, ela não pode dizer nada baseada em suas palavras.

E: Mas com base em minhas palavras, digo que no norte, onde há sempre neve, os ursos são brancos. Você pode entender que tipos de ursos existem em Novaya Zemlya? S: se um homem de 60 ou 80 anos tivesse visto um urso branco e tivesse contado sobre isso, se acreditaria nele, mas eu nunca vi um e, portanto, não posso dizer. Esta é a minha última palavra. Aqueles que viram podem dizer e aqueles que não viram não podem dizer nada! (Luria, 1990, p. 145).

Tendo em vista a maneira como Luria conduz a entrevista (ou seja, de modo direto e utilizando-se de termos familiares ao entrevistado), fica difícil alegar que o entrevistado não entendeu a pergunta e que a inferência silogística possa ser tida por uma universal cognitiva, de modo que somos levados a crer que, de fato, parece haver aspectos da cognição que não podem ser generalizados.

De fato, a julgar pelo modo como Oliveira (1999) coloca as questões acima arroladas, parece óbvio que inconsistências teóricas decorreriam de uma abordagem que não levasse em conta diferenças "essenciais" entre as ciências humanas e as ciências naturais. Entretanto, a sugestão de simplesmente dividir-se as ciências cognitivas entre ciência cognitiva natural e ciência cognitiva cultural, a nosso entender, traria mais problemas que soluções ao seio das ciências cognitivas. Isso porque acreditamos na integração entre os saberes (historicamente já tão fragmentados e ainda em 
processo de divisão), tendo em mira a compreensão de um objeto comum, a saber: os fenômenos ligados à cognição.

Além disso, e a despeito do temor de cairmos num discurso retórico, entendemos que a própria terminologia essencialista de Oliveira denuncia uma postura que a todo o custo queremos evitar por considerá-la errônea. Isso porque, ao afirmar que haveria diferenças "essenciais" entre as ciências humanas e as naturais, o autor utiliza-se de um termo metafísico largamente utilizado pelos medievais e modernos (essência), dando a entender que fenômenos naturais e fenômenos culturais, por exemplo, referir-se-iam a realidades ontológicas distintas, algo passível de contestação.

\section{Conclusão}

Tendo em vista a sequência de textos da obra Da ciência cognitiva à dialética, sobretudo o capítulo IV, intitulado "natureza e cultura", parece-nos claro que a intenção do autor não seja a descrita acima (daí destacarmos nosso temor de cairmos num discurso retórico), de modo que, por diferenças essenciais, o autor talvez queira dizer que os aspectos que ele chama de naturais da cognição deveriam receber uma abordagem metodológica e conceitual distinta dos aspectos culturais da cognição.

Entretanto, o ponto a que gostaríamos de chegar neste artigo é o de que um dos pressupostos adotados por nós consiste em entender que não haveria uma dicotomia entre natureza e cultura, de modo que, pelo menos a princípio, seria possível procurar desenvolver uma espécie de naturalização da cultura. Pois, no presente momento da história, e a despeito das evidentes especificidades entre os saberes, urge que nos empenhemos em encontrar uma maneira de promover uma espécie de "canal de diálogo" entre as ciências, de modo que o naturalismo que advogamos não se confunda com o naturalismo fisicalista, que consiste em generalizar os conceitos e métodos 
das ciências naturais às demais ciências, reduzindo estas àquelas. Nesta perspectiva, separar a ciência cognitiva em dois domínios parece-nos em nada contribuir para o progresso de uma disciplina que se propõe interdisciplinar, e está empenhada em isolar características comuns às diversas especialidades científicas ${ }^{6}$.

Acreditamos, a rigor, que seja possível estabelecer um patamar comum entre as ciências que estudam a mente, e que, no entanto, seja crítica, reconhecendo que diferenças entre objetos da natureza, apesar de existirem, não são inconciliáveis. Nesse sentido, ao nos referirmos ao naturalismo, não estamos tomando o conceito em seu significado usual, mas queremos dizer que todos os fenômenos estudados pelo homem são naturais (no sentido de que nada há de sobrenatural), ou seja, estão circunscritos num círculo mais abrangente (a natureza, no caso) que qualquer uma das ciências particulares.

Havendo um ponto de toque entre os fenômenos biológicos e culturais, esses âmbitos estando sob um guarda chuva comum (a natureza), nos parece evidente que instrumentos epistemológicos possam ser discutidos num esforço conjunto de intercâmbio interdisciplinar.

Uma maneira de ilustrarmos o que queremos dizer seria afirmar que os experimentos de Luria com camponeses da extinta URSS, antes de revelar que universais cognitivos de ordem superior (tais como a inferência silogística, no caso de seu experimento) não existem, nos mostra que o problema que realmente deveria ser colocado e investigado seria: quais os mecanismos subjacentes às relações entre os camponeses da região estudada e o ambiente no qual estão inseridos permitiram que o padrão cultural emergente não soubesse lidar com um tipo de inferência lógica

6 No livro General system theory (1968), por exemplo, Von Bertalanffy afirma que pensar na unificação entre as ciências seria viável não apenas por ser possível estabelecer uma analogia entre vários aspectos das ciências particulares, mas sim pelo fato de tais isomorfismos suscitarem a possibilidade real de se aplicar certos instrumentos epistemológicos a fenômenos naturais diversos.

(C) Filosofia e Educação - ISSN 1984-9605 - Volume 4, Número 2

Outubro de 2012 - Março de 2013 
aparentemente tão simples para nós ocidentais, inseridos numa sociedade de capitalismo avançado?

Fazendo um breve parêntese, gostaríamos de explicitar que, na abordagem sistêmica que advogamos, o homem é entendido como indissociável de seu meio natural, de modo que, em tal perspectiva, o que realmente interessa são os processos e relações entre os componentes do sistema, uma abordagem evidentemente distinta do paradigma mecanicista que, grosso modo, propõe uma abordagem fisicalista, atribuindo ao homem o papel de observador destacado do mundo, com estados mentais como que dissociados de seu objeto de estudo, de modo que, por meio do método analítico, tal objeto seria isolado de seu meio natural e dividido em partes para ser "melhor" entendido".

Entendemos que o temor de Oliveira (1999) a respeito dos possíveis problemas de se tomar por naturais os aspectos da cognição que, de fato, seriam culturais, talvez não se coloque caso se adote uma perspectiva que não enxerga fronteiras tão nítidas entre natureza e cultura. Entretanto, devemos deixar claro que, apesar de não concordarmos com o autor quanto à ideia de se separar a ciência cognitiva em dois domínios, reconhecemos (e nisso estamos de pleno acordo com ele) que confusões referentes aos planos de análise possam ocorrer. Ou seja, confusões no que tange ao recorte epistemológico adequado ao problema que se queira resolver não só podem ocorrer, como, de fato, são frequentes em estudos que se propõem a investigar fenômenos complexos. Mas mesmo reconhecendo esta possibilidade, ainda assim insistimos que a divisão pura e simples da ciência cognitiva em dois domínios, cada qual com seus próprios instrumentos

7 Para Dewey (1980), por exemplo, os problemas da filosofia surgiram de seu afastamento do que ele denomina "experiência primária". Quando os filósofos deixam de lado a experiência primária, na qual sujeito e objeto do conhecimento estariam inextricavelmente unidos, ao ser julgada como aparente e entendida como mera impressão ontologicamente inferior a uma realidade última e essencial, acabaram por decretar, para Dewey, a morte da filosofia verdadeiramente séria e eficiente.

(C) Filosofia e Educação - ISSN 1984-9605 - Volume 4, Número 2

Outubro de 2012 - Março de 2013 
epistemológicos e conceituais, não traria avanços significativos quanto à compreensão integral dos fenômenos cognitivos.

Por fim, parece-nos que o naturalismo que advogamos, por ser mais geral, engloba o naturalismo fisicalista usual, e que, apesar da suscetibilidade de confusão entre planos de análise (que, como vimos, é a principal preocupação de Oliveira), ainda assim acreditamos que seja a melhor alternativa de que dispomos para se pensar nas relações e na caracterização das fronteiras entre os saberes.

\section{Referências}

DENNETT, D. Somos todos robôs. Entrevista à revista Istoé. São Paulo, Editora Três, 16/11/1996, p.5-7.

DEWEY, J. Experiência e natureza. Tradução de Murilo Otávio Rodrigues Paes Leme. São Paulo: Abril Cultural, 1974. (Coleção Os Pensadores). P.159-210.

GARDNER, H. A nova ciência da mente: uma história da revolução cognitiva. Tradução de Cláudia Melbergier Caon. São Paulo: Edusp, 1995.

LURIA, A. R. Desenvolvimento cognitivo: seus fundamentos culturais e sociais. Tradução de Luiz Mena Barreto, Marta Kohl Oliveira, Miriam M. M. de Andrade e Regina Heloísa Maciel. São Paulo: Ícone editora, 1990.

OLIVEIRA, M. B. Da ciência cognitiva à dialética. São Paulo: Discurso Editorial, 1999.

POPPER, K. R. Conjecturas e refutações. Tradução de Sérgio Bath. Brasília: Editora da universidade de Brasília, 1972. (Coleção pensamento científico). - A miséria do historicismo. São Paulo: Cultrix/Edusp, 1980.

- Auto biografia intelectual. São Paulo: Cultrix, 1977.

A sociedade aberta e seus inimigos. São Paulo: Edusp, Belo Horizonte:

Itatiaia, 1974.

. Objective knowledge: an evolutionary approach. Oxford: Clarendon, 1979.

Indeterminism in quantum physics and in classical physics. British journal of the philosophy of science, vol. I, p. 173-195, 1950.

. The Open Universe: an argument for indeterminism. London: Hutchinson, 1982. (Postscript: after twenty years, 2).

VON BERTALANFFY, L. General system theory. New York: N. Y. Press, 1968. 